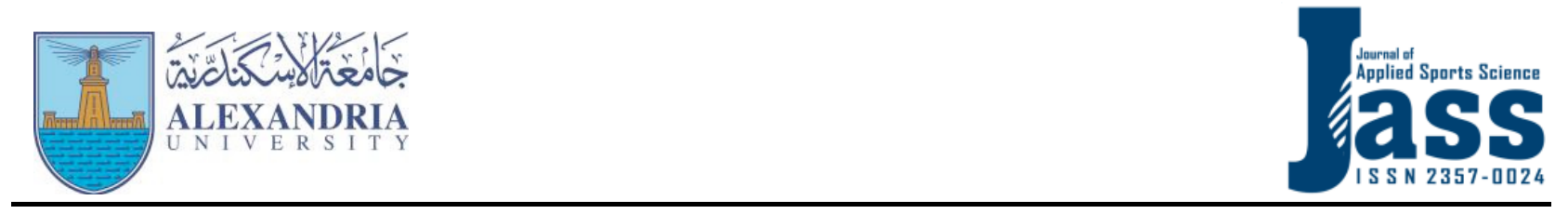

\title{
The effectiveness of brain-based learning strategy in the light of blended learning on the cognitive achievement
}

\author{
Fatma A. Saber1, Nadia Z. Elhamoly2, Ashraf S. Yunis3, Ehab O. Eissa4 \\ 1Professor, Faculty of Sport Education for men, Dep. school sport, Alexandria University, Egypt \\ 2Professor, Faculty of Sport Education for men, Dep. school sport, Alexandria University, Egypt \\ 3Assistant Professor, Faculty of Sport Education for men, Dep. school sport, Alexandria University, \\ Egypt
}

4Assistant lecturer, Faculty of Sport Education for men, Dep. school sport, Alexandria University, Egypt

\begin{abstract}
Identify the impact of the proposed guide based on the brain-based learning strategy in the light of blended learning to reflect on the academic achievement of the movement education curriculum for the students of teaching specialization at the Faculty of Physical Education.

The researcher used the experimental approach by designing one experimental group applying the pre and post measurements. The research was randomly conducted on a sample of (20) fourth-year students of teaching specialization at the Faculty of Physical Education for Boys, Alexandria University.

The researcher designed the academic achievement test for the movement education curriculum using the brainbased learning strategy in the light of blended learning, as well as the suggested guide for teaching the movement education curriculum based on the brain-based learning strategy in the light of blended learning. The most important results were that the use of the brain-based learning strategy in the light of blended learning was an effective method of teaching, as well as There is a high percentage improvement between the pre and post measurements of the experimental group, which used a brain-based learning strategy in the academic achievement test in favor of the dimensional measurements.
\end{abstract}

Keywords: brain-based learning strategy, blended learning, cognitive achievement 


\section{Introduction and research problem:}

Today, the world lives in an era of tremendous scientific development and advances in all areas of life, As it imposes amazing challenges on the educational process, Its objectives evolved into preparing a learner capable of successful interaction with life, forming an advanced thought and conscious mind, refining mental skills, and developing supra- academic processes.

This requires societies to face these challenges, Therefore, educational research competed in the search for modern methods appropriate to the nature and challenges of the era of practical progress.

Hence, educators should pay attention to creating and preparing educational programs, methods, and strategies appropriate to the circumstances and capabilities of learners, which based on developments and modern scientific theories that are able to prepare the learner with a creative, effective mind capable of interacting with this development, Perhaps one of the most important of these is the results of research into the dynamics of the human brain and its educational applications in this field, which resulted in the appearance of the Brain-based learning theory. (Eltity 2014)

The brain-based learning theory is one of the theories of learning that appeared in the last decade of the last century, Where it was announced at the time that it was a "brain decade" as a result of the huge discoveries in its structure and functions, Which confirms its characteristics it is a system in its own right and not a pre-designed design. Rather, it is a multi-system trend as it derives from a number of systems such as chemistry, neuroscience, psychology, genetic engineering, biology, and computer science, This marked the birth of the theory of brain-based learning, and the strategy for brain-based learning emerged from it. (eric 2005)

This theory is based on several principles and foundations, the most important of which are mentioned by Caine and Caine (1991) and Afanah and al gaish (2009), as follows:

- The brain is a parallel processor, Learning engages the entire physiology, The search for meaning is innate, The search for meaning occurs through "patterning", Emotions are critical to patterning, The brain processes parts and wholes simultaneously, Learning involves both focused attention and peripheral perception, Learning always involves conscious and unconscious processes, We have at least two different types of memory: a spatial memory system and a set of systems for rote Learning, We understand and remember best when facts and skills are embedded in natural, spatial memory, Learning is enhanced by challenge and inhibited by threat, Each brain is unique. 
Most references and literature indicate that the brain-based learning strategy includes five stages, Afanah and the al gaish (2009) cited the following stages: predisposition to learning, orchestrated immersion, relaxed alertness, active processing, and expanding of brain capacity.

As educational studies revealed that the brain-based learning strategy has an effective role in developing traditional methods of teaching, and applying its principles leads to achieving meaningful learning and organizing education according to the structure of the brain, Providing educational opportunities for all learners of all abilities, Stimulating learning and being actively involved in it, And directing scientific behavior to use science processes and skills with a scientific methodology in research and thinking, This leads to raising the level of students and their educational capabilities and improving the level of achievement and accepts scientific knowledge, their interaction with it, acquisition, retention, and employment it in their daily life.

One of the main objectives of the educational process is to increase academic achievement and raise the level of the learner's assimilation of information and ideas that he may employ within his daily experiences, So that learners can transform knowledge into a useful daily application and behavior, from which we can draw future aspirations and goals. (eltity 2014)

The results of some studies and research have also shown that activating the role of the brain by creating the appropriate environment for the learning process is an important factor in raising the level of academic achievement of learners. Therefore, the application of a brain-based learning strategy, and the diversification of teaching strategies that are in harmony with the brain and activate it in the best way lead to obtaining the best results from the learning process.

Therefore, educational institutions and educationalists took great care to educate learners and raise the level of academic achievement and its quality for them, As this constitutes all educational reforms, and The problem of its decline is one of the most difficult problems to understand, diagnose, and treat. Because its causes are multiple and intertwined and it has educational, economic, social, cultural, and psychological dimensions, this made it an issue for continued academic research, which is the goal that the researcher seeks. 
Blended learning is considered one of the modern forms of education that combines the advantages of e learning/e-education and face-to-face learning education to eliminate the disadvantages of each in an attempt to meet educational needs and provide an effective educational environment. (Ashraf Sobhy 2011)

In light of the continuous development of learning technologies and methods of presenting content, educational institutions will be biased towards blended learning on one-style programs, especially with regard to the achievement of their performance and educational objectives to achieve the best results in terms of cost, time and quality. Badr al khan (2005)

From the above, it is clear to the extreme importance of modern educational applications and developed teaching strategies, foremost of which is a brain-based learning strategy, and its use to serve the educational process in the light of blended learning and to solve some of the problems it faces, and the importance of its application and use in the educational process in various stages of life in line with contemporary trends and modern technologies, The previous studies also confirmed the importance of designing and providing a stimulating educational environment that is free from threat and tension and is characterized by suspense and excitement, also, it becomes clear the importance of academic achievement and the importance of improving it For undergraduates, Therefore, the researcher sought to use it to develop academic achievement and the functional application of that knowledge that students acquire in teaching a course of the movement education, Which is of benefit to raise their level and their teaching competencies and improve their job performance and prepare them for the teaching profession distinctly, as this is reflected in the education of learners by raising generations able to think in a scientific way to adapt to the variables of this age, and contribute effectively to achieving the goals of society, For the researcher, through reviewing and analyzing many of the previous references and studies that dealt with research and exploration of modern teaching methods and strategies, it became apparent that there was a dearth of studies conducted on the brain-based learning strategy in the field of physical education, And that this area still needs to conduct many studies and research, This prompted the researcher to try to identify the effect of the brainbased learning strategy in the light of blended learning on academic achievement in the movement Education curriculum for the students of teaching specialization 


\section{Research Objective:}

\section{The research aims to: -}

The main objective of the research is to investigate the effect of the guide based on the Brain-based learning strategy in the light of blended learning on the academic achievement of the movement education curriculum for the students of teaching specialization at the Faculty of Physical Education.

\section{This is achieved through the following steps:}

1- Designing a guide for the instructor of movement education using the brain-based learning strategy in the light of blended learning.

2- Designing a guide for students of teaching specialization in the teaching of the movement Education curriculum using the brain-based learning strategy in the light of blended learning.

3- Designing a academic achievement test for movement education using the brain-based learning strategy in the light of blended learning.

4- Applying the brain-based learning strategy in the light of blended learning for academic achievement in the movement education curriculum for the students teaching specialization.

5- Identify the significance of the differences in academic achievement of the movement Education curriculum for the students of teaching specialization using the brain-based learning strategy in the light of blended learning.

\section{Research Hypotheses:}

1- There are statistically significant differences between the mean scores of the pre-test and post-test measurements of the experimental group in the academic achievement test of the movement Education curriculum for the students of teaching specialization.

\section{Research Procedures:}

\section{Research Methodology:}

The researcher used the experimental method for one experimental grup by conducting the pre- and post-measurements for the experimental group so as to the suitability of the nature of the research, The present study compares the effects of independent variables of the study (brain based learning in the light of blended learning strategy used in the experimental group between the pre and post measurements on the dependent variable (student academic achievement). 


\section{Research Community and Sample:}

The study was carried out by the researcher among fourth-year students of teaching specialization at the Faculty of Physical Education for Boys in Abu Qir - Alexandria University in the 2019-2020 academic year, The researcher randomly selected the research sample and the study group of the research consists of 20 students applied to them teaching using Brain-based learning strategy in the light of blended learning by the researcher.

\section{Instruments:}

- A proposed guide based on the Brain-based learning strategy in the light of blended learning in the movement education curriculum for the students of Teaching specialization was designed by the researcher.

- Achievement test was used in this study as a research tool because the aim of the research was to investigate the effect of brain-based learning strategy on the academic achievement. The items for the test were designed by the researcher.

\section{Procedure of the research:}

\section{tribal Measurements:}

The measurements were performed for experimental research group, for the academic achievement test, on 24/2020.

The Research procedures for the experimental group: The researcher assigned a lecture to train the students of the experimental group on the brain based learning strategy in the light of blended learning and teaching it because there is no background knowledge of the students and during the study Teaching was done with the steps included in the brain-based learning strategy by creating a learning environment that is in line with the principles of the brain and diversity in teaching strategies that develop both sides of the brain with training on educational activities and conducting discussions and answering the staging and final evaluation and doing household assignments as well as the researcher performs feedback and guides students. 


\section{Post measurements:}

After completing the research for the experimental group, the post measurements were made under the same conditions of the tribal measurements in the academic achievement

\section{Statistical Treatments:}

The following statistical treatments were found by using the "SPSS version 20" software:

- Mean

-Mediator

-standard deviation

- Median

- Skewness

- Kurtosis

- Paired Samples T test

- independent $\mathrm{T}$ test Samples

- Percentage

- The percentage of improvement

- Effect Size

- ETA Square

\section{Results and Discussion:}

Findings and comments are presented according to the below research hypothesis.

1- There are statistically significant differences between the mean scores of the pre-test and post-test measurements of the experimental group in the academic achievement test of the movement Education curriculum for the students of teaching specialization

First of the academic achievement pre and post test score averages $(\mathrm{X})$ and the standard deviation $( \pm Y)$ of the experimental group have been calculated and a Paired Samples T test has been applied. The results of the analysis have been given in Table 1,2 and graph 1,2. 
Table (1)

Statistical indications of the academic achievement test Percentage Improvement rate for the experimental group and the control group before and after the experiment

\begin{tabular}{|c|c|c|c|c|c|c|c|c|c|}
\hline \multirow{2}{*}{ Variable } & \multicolumn{2}{|c|}{ Pre test } & \multicolumn{2}{|c|}{ Post test } & \multicolumn{2}{|c|}{$\begin{array}{c}\text { Difference } \\
\text { Between the } \\
\text { averages }\end{array}$} & \multirow{2}{*}{$\begin{array}{l}\text { Value } \\
\text { (t) }\end{array}$} & \multirow{2}{*}{$\begin{array}{l}\text { Error } \\
\text { level }\end{array}$} & \multirow{2}{*}{$\begin{array}{l}\text { Improvement } \\
\text { Percentage \% }\end{array}$} \\
\hline & $x$ & $\pm Y$ & $x$ & $\pm Y$ & $x$ & $\pm Y$ & & & \\
\hline $\begin{array}{c}\text { academic } \\
\text { achievement test }\end{array}$ & 31.50 & 5.52 & 55.25 & 11.70 & 23.75 & 11.35 & $9.35 *$ & 0.00 & $75.40 \%$ \\
\hline
\end{tabular}

${ }^{*}$ Morale at the level of $0.05=2.09$

It is clear from Table (1) and the graph (1) of the statistical significance of the academic achievement test for the experimental groups before and after the experiment: There are differences with a statistical error at the level of $(0.05)$ where the value of $(\mathrm{T})$ calculated in it $\left(9.35^{*}\right)$ and this value is greater than the value $(\mathrm{C})$ Tabularity is at the level of $(0.05)=(2.02)$ with an error level of less than 0.05 , and the Improvement percentages in the academic achievement test under discussion reached $(75.40 \%)$ in favor of the post measurement

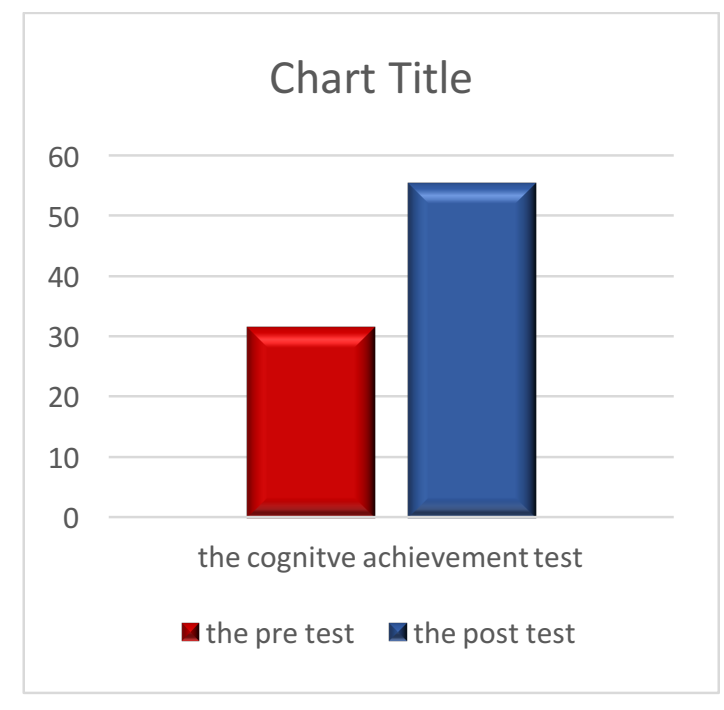

Graph (1) illustrates the differences between the averages of the pre and post measurements of the the academic achievement test Percentage Improvement rate for the experimental group and the control group before and after the experiment 


\section{Table (2)}

The magnitude of the academic achievement test Percentage Improvement rate for the experimental group and the control group before and after the experiment according to Cohn's equations.

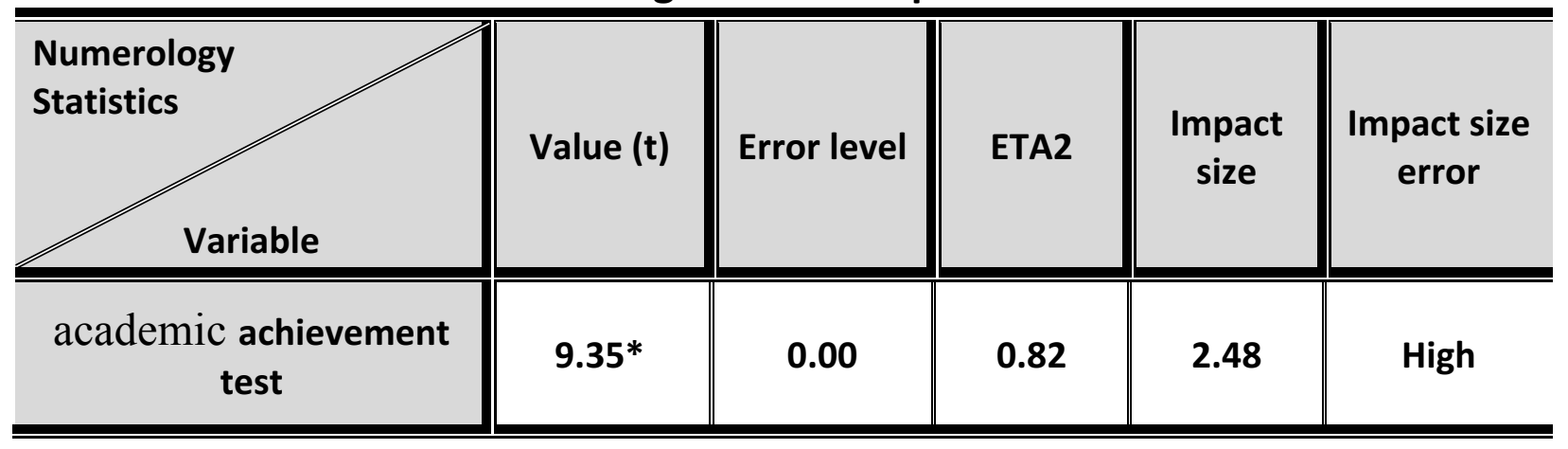

Impact size: Less than 0.5: Low 0.5-0.8: Average 0.8 and above: High -

It is clear from the (2) and the graph (2) of scale of the magnitude of the impact volume of the academic achievement test for the experimental group according to The Equations of Cohn that the values of the magnitude of the impact amounted to (2.48) and this value is greater than (0.8) and therefore the effect of the experimental variable was high in the total of the academic achievement test.

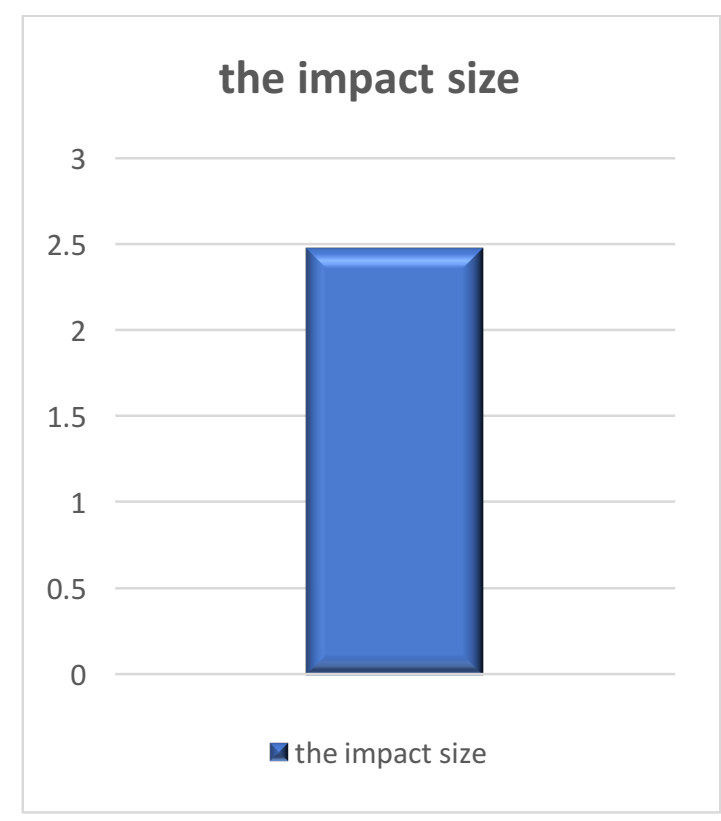

Graph (2) shows the magnitude of the effect of the the academic achievement test under consideration for the experimental group according to Cohn's equations 
As a result, It was evident from Tables 1, 2 and Figure 1, 2, it was observed to be a statistically significant difference between the pre-measurement and the postmeasurement after the experimental procedure in favor of the post-measurement in the academic achievement test for the students of teaching specialization in the movement education curriculum

Besides, after the experimental procedure, it was observed that there is a significant difference in the academic achievement level

Various studies show that brain-based learning has effective role in improving student achievement. For instance, according to the results of the study, Miller (2003) and OKTAY, ÇAKIR (2013) argues that brain-based learning is a strategy to help students learn, increase their capacity and academic achievement when linked to today's teaching environment That matches the principles of the brain With brain structure and functions

brain-based learning strategy more significantly increased the students' academic achievement when compared to traditional teaching method. This finding concurs with the literature (Brodnax, 2004; Özden and Gültekin, 2008; Bilal DUMAN 2010).

When the planning, presentation and gains of the lesson are in compliance with the working principles of the brain, positive contributions can be made to students' motivation, attitudes, and academic achievement (Bilal DUMAN 2010; Kotulak, 1997;).

We can argue that the BBL model used in the present study provided an environment and process based on "the natural learning conditions of brain" for students with different learning styles. (Bilal DUMAN 2010)

The students have benefited greatly from the blended learning and this was reflected in the high level of academic achievement, their acquisition of information, and the formation of positive trends towards blended learning. This result is consistent with the result study of (Ashraf Sobhy 2011), which stated: In order for blended learning to achieve effectiveness, the teacher must have the ability to understand, building And applying different Merging strategies to a group of students who have the ability and skill in dealing with Various merging Means and regulating the nature of performance between the teacher and the learner. (Ashraf Sobhy 2011) 


\section{I) Conclusions:}

Based on the results and according to the research objectives, hypotheses and methodology the following conclusions were reached:

- There is a high percentage improvement between the pre and post measurements of the experimental group, which used a brain-based learning strategy in the light of blended learning in the academic achievement test in favor of the dimensional measurements.

\section{II) Recommendations:}

Based on the results of the current study, the researcher recommends the following: 1- Conducting more scientific research on using the brain-based learning strategy in the light of blended learning for other variables and curricula in the faculties of physical education at the various academic levels.

2- Conducting more scientific research on the use of the brain-based learning strategy in the light of blended learning and measuring its effectiveness in developing many learning outcomes for different groups of learners.

3- The inclusion of a brain-based learning strategy in the light of blended learning within the curricula of the school sports program to prepare students in the Faculty of Physical Education, which is reflected at the level of learners who study for them.

5- Holding courses, seminars and workshops for teachers, mentors, supervisors and faculty members in the Faculties of Physical Education to identify the trends and modern teaching strategies and their types in general and the brain-based learning strategy in the light of blended learning in particular, and how to apply it in physical education teaching .

6- Reconsidering the plans and programs for preparing the teacher students in the faculties of physical education in line with the requirements of the times and the programs and modern strategies for preparing a teacher capable of good behavior and making decisions during teaching after graduation. 


\section{References :}

1- Ashraf sobhy yunis , (2011), effectiveness of program based on blended learning to improve teaching skills knowledgeable fum direction for e-learning for students teacher in sport education for men, unpolished $\mathrm{PhD}$, thesis, faculty of physical education, Alexandria university.

2- Badr al khan (2005), E-Learning Strategies, translated by Ali bin Mushrif Al-Dorsi, Salem bin Jaber Al-Rafi'i, Mona Al-Tiji, Beam for Publishing and Science, Rabat Lane

3- Bilal DUMAN, (2010), The Effects of Brain-Based Learning on the Academic Achievement of Students with Different Learning Styles, Educational Sciences: Theory \& Practice, 10 (4) • Autumn 2010 • 2077-2103

4- Brodnax, R. (2004), BRAIN COMPATIBLE TEACHING FOR LEARNING. UMI Microform 3173526 Copyright 2005 by ProQuest Information and Learning Company

5- Caine, R. \& Caine, G.(1991), Understanding a Brain-Based Approach to Learning and Teaching. Educational Leadership, 48 (2), 66-70

6- Ezzo afanah, ismaeil al gaish (2009), Teaching and Learning with the Two Sided Brain, Afaq Publishing and Distribution House, Gaza, Palestine.

7- Jensen, Eric (2005), teaching with the brain in mind. 2th edition. Association for supervision and curriculum development Alexandria, Virginia, USA.

8- Kotulak, D. (1997). Recognition memory, circadian rhythms, and sleep. Perceptual Motor Skills, 85 (1), 99-104.

9- Miller, A. L.,(2003). A descriptive case study of the Implementation of brain-based learning with technological support in a rural high school. Ph. D. Thesis, Northern Illinois University,

10- Moslem eltity (2014), the impact of an instructional program based on brain on motivation, achievement and scientific thinking of the $5^{\text {th }}$ grade students, unpublished phd, faculty of education, elyarmok university.

11- Ozden, Muhammet and Gultekin, Mehmet, (2008),The Effects of Brain-Based Learning on Academic Achievement and Retention of Knowledge in Science Course. Electronic Journal of Science Education (Southwestern University). 12 (1) ,1-17.

12- Senem OKTAY1, Recep ÇAKIR 2013 The Effect of Technology Supported Brain Based Learning on Students' Academic Achievement, Retention Level and Meta academic Awareness Journal of TURKISH SCIENCE EDUCATION Volume 10, Issue 3, September 2013 